Macedonian Pharmaceutical Bulletin, 66 (Suppl 1) 233 - 234 (2020)

Online ISSN 1857 - 8969

UDC: $615.461 / .466 .065: 616.314-77$

DOI: 10.33320/maced.pharm.bull.2020.66.03.116

Short communication

\title{
Dental prosthetic materials and adverse drug reactions in everyday prosthodontic practice
}

\author{
Borjan Naumovski ${ }^{1}$, Vesna Jurukovska Shotarovska ${ }^{2}$, Aneta Mijoska $^{2}$, \\ Sasho Elenchevski ${ }^{2}$ \\ ${ }^{1}$ University Dental Clinical Centre St. Panteleimon- Skopje, Str. Majka Tereza 47, 1000 Skopje, RN Macedonia \\ ${ }^{2}$ Dental Faculty, University "Ss. Cyril and Methodius", Skopje, RN Macedonia
}

\section{Introduction}

Prosthodontics is a dental medicine branch that resurrects and restores the missing teeth to reestablished masticatory and phonetic functions, appearance and health of the patient in order to maintain the natural state of stomatognathic system. It embraces different dental restorations, including complete dentures (CDs), fixed partial dentures (FPDs), removable partial dentures (RPDs) or implant-assisted prostheses. Dental alloys, polymer materials, acrylic resins, ceramics, cements, sealers, etchants, solutions for oral disinfection, waxes and elastomeric impressions are the most commonly used materials in prosthodontic clinical practice. During the dental procedure, patients and the medical staff are exposed to potentially harmful and irritating compounds of the used dental materials. The degradation of these biomaterials may cause various health problems and side effects. (Asal et al., 2017) The aim of this study is to evaluate the risks of adverse reactions regarding prosthodontic materials.

\section{Materials in clinical prosthodontic}

Restorative materials, impression materials and

\footnotetext{
*naumovskiborjan@gmail.com
}

* naumovskiborjan@gmail.com luting cements are three groups of most commonly used materials in clinical prosthodontics.

\section{Restorative materials}

Clinical prosthodontic treatment includes CD and RPD, FPD, superstructures over implants and veneers made utilizing ceramics, polymers and metal alloys.

Ceramics. Dental ceramics are made of metal oxides and half metals $\left(\mathrm{K}_{2} \mathrm{O}, \mathrm{CaO}, \mathrm{MgO}, \mathrm{Al}_{2} \mathrm{O}_{3}\right.$, $\mathrm{B}_{2} \mathrm{O}_{3}$ and $\mathrm{SiO}_{2}$ ).

Polymers. Polymer-based materials are used for production of veneers for crowns, FPDs, CD and RPD. Dental technicians, during the process of production of dental prosthesis, are operating with various polymers and monomers, (poly) substituted acrylic acid esters, polyvinyl esters, polyacrylic acid esters, rubber-modified polymetacrylic esters, polystyrene, polysulfones, polycarbonates and mixtures of different polymers.

Metals alloys. Most frequently used dental alloys for production of partial and fixed denture frameworks are composed of the following elements: Co (60-65\%), Cr (27-30\%), Mo (5-6\%), $\mathrm{Ni}(\leq 0.5 \%$, but may exceed up to $10 \%), \mathrm{Ag}, \mathrm{Cu}, \mathrm{Pd}$, $\mathrm{Sn}, \mathrm{Au}, \mathrm{In}, \mathrm{Zn}$ and $\mathrm{Hg}$. Some metals, if highly concentrated, can trigger toxic reactions in human body such as hypersensitivity, generalized and local skin reactions, reported by prosthodontic specialists worldwide. 


\section{Impression materials}

There are two main groups of impression materials: elastic (hydrocolloids and elastomer) and non-elastic (gypsum products, wax materials and thermoplastic materials). Elastomers are classified into 3 groups: polymer-based elastomers, type A (addition-polymerized) and $\mathrm{C}$ (condensationpolymerized) silicones, polyethers and polysulfides.

\section{Luting cements}

Luting cements are used to temporarily or permanently merge crowns and fixed partial dentures (FPD) with previously prepared teeth. Water-based (glass-ionomer, zinc polycarboxylate and zinc phosphate), as well as polymer-based types of cements (polymer materials, composites, and compomers) are commonly used in everyday prosthodontic practice. (Lygre, 2002)

\section{Adverse reactions of prosthodontic materials}

Biological systems may have harmful or destructive effects on materials, recognized as biodegradation. Biodegradation of the dental materials used in the oral cavity is due to the processes of destruction and dissolution in saliva, chemical/physical destruction, attire and erosion caused by food, chewing and bacterial activity.

Alloys used in prosthetic dentistry release ions; the process is gradual, long lasting, characterized with continuous discharge of small amounts of substances. The small sized compounds released from dental restorations are absorbed in oral mucosa or the gastrointestinal tract and respiratory system. Biodegradation, initiated by the contact with saliva and biomaterials form the dental crafts, may instigate processes of hydrolysis or electrolysis, resulting in release of compounds in the oral cavity and promotion of adverse reaction for the patient.

Most dental materials are intended for long-term use and patients may be sensitized with the exposure, resulting in contact allergies, characterized with diversity in the clinical manifestations. Hypersensitivity reactions may affect the oral mucosa, with burning and pain, or appear as more objective manifestations, localized to the buccal mucosa, tongue, and lips, including stomatitis protetica, cheilitis and lichenoid reactions. Dental professionals can get hand dermatitis from using dental materials and products. Patch testing is recommended to detect contact allergies from complete and partial dentures containing the most frequently used dental materials. (Rai et al., 2014)

Hypersensitivity reactions are classified into following four different types: Type I-IV, anaphylactic antibody-mediated reactions, (most common), cytolytic or cytotoxic reactions, immune complex reactions and delayed-type hypersensitivity reaction, respectively.

Beside the vast majority of all prosthodontic dental materials available in our country and their utilization in everyday dental practice, there are no reports of adverse events associated with these materials. The main reason for this underreporting lays in the lack of awareness of the importance of adverse event reporting, lack of education program for dental specialists, technicians, nurses and patients and lack of established system for evaluation of risk/benefit ratio of dental materials.

\section{Conclusion}

Implementation of appropriate strategy to raise the awareness of the importance of adverse events reporting for dental materials used in prosthodontics, entailing educational program with workshops and practical aspects regarding materiovigilance for both dental doctors and patients, alongside with contemporary software infrastructure available on MALMED- Macedonian National Regulatory Agency, could be a successful approach for improvement of adverse event reporting in everyday dental practices. This approach has a pivotal role in obtaining effective and safe treatment and collecting inevitable information for the quality of dental materials utilized among dental health care professionals on national level.

\section{References}

Asal, S.A., Fattah, F.E.A., 2017. Hazards of prosthodontic devices and materials. Tanta Dental Journal 14(1), 711

Lygre, H., 2002. Prosthodontic biomaterials and adverse reactions: a critical review of the clinical and research literature. Acta Odontol. Scand. 60, 1-9

Rai, R., Dinakar, D., Kurian, S.S., Bindoo, Y.A., 2020. Investigation of contact allergy to dental materials by patch testing. Indian Dermatology Online Journal 5(3), 282-286.

Maced. Pharm. Bull. 66 (Suppl 1) 233 - 234 (2020) 